\title{
Um Rio de Janeiro feérico e decadente
}

\author{
Laura Taddei Brandini*
}

\begin{abstract}
RESUMO: O presente artigo tem por objetivo analisar o olhar do escritor francês Gilles Lapouge sobre o Rio de Janeiro a partir da leitura do verbete dedicado à cidade em seu Dictionnaire Amoureux du Brésil, publicado em 2011. Os diálogos com outros escritores-viajantes que conheceram o Rio, como Stefan Zweig, ou com o escritor que buscava, no tema da viagem, evadir-se da realidade, Baudelaire, conduzem a construção da imagem da cidade para Lapouge, oscilando entre um Rio de Janeiro feérico e decadente.
\end{abstract}

Palavras-chave: Gilles Lapouge; Rio de Janeiro; escritores-viajantes.

A experiência da viagem com frequência é pródiga quando vivenciada por um escritor, como se nota quando se tem a dimensão do verdadeiro continente de livros que compõe a dita "literatura de viagem". Subgênero literário dos mais tradicionais, somente no século XIX consagrou-se e no século XXI tem tido seu espaço ampliado, notadamente no âmbito da Literatura-Mundo, uma das configurações atuais da Literatura Comparada. O teórico estadunidense David Damrosch reuniu os fundamentos da Literatura-Mundo em seu livro What is World Literature ? (2003), tendo como ponto de partida a Weltliteratur de Goethe (1827) e definindo a Literatura-Mundo como segue:

\begin{abstract}
Considero a Literatura-Mundo como algo que compreende todas as obras literárias que circulam para além de sua cultura de origem, seja em tradução ou em língua original [...]. Em seu sentido mais amplo, a Literatura-Mundo pode incluir qualquer obra que alguma vez tenha ultrapassado sua base [...]: uma obra só tem uma vida efetiva enquanto Literatura-Mundo quando, e onde estiver ativamente presente dentro de um sistema literário além do de sua cultura de origem. ${ }^{\mathrm{i}}$ (2003, p. 04)
\end{abstract}

A Literatura-Mundo se fundamenta no princípio da circulação, como se pode notar pela citação acima. Nesse sentido, as obras da Literatura-Mundo podem ser vistas de três modos: "como um corpo estabelecido de clássicos, como um cânone ampliado de obrasprimas ou como múltiplas janelas para o mundo" (2003, p. 15, grifos do autor). Claro que dessas três compreensões a última é a mais interessante: pensar em textos como "janelas para o mundo" permite imaginá-los como amostras de mundos maiores à espera de seus exploradores, os leitores. Nessa circulação, têm lugar obras literárias oriundas de culturas fora do mainstream político-econômico, de países e regiões que pouco aparecem nas estantes das grandes livrarias europeias e norte-americanas, e ganha destaque toda a literatura produzida pelos viajantes que encontram, nessas culturas pouco conhecidas, terreno fértil para plantar suas narrativas. $\mathrm{O}$ atual boom da literatura de viagem se verifica no circuito comercial, como atestam os festivais literários inteiramente a ela dedicados como, por exemplo, o Festival Literatura em Viagem, realizado em Matosinhos, Portugal (12 ${ }^{a}$ edição em 2018), o Immrama Festival of Travel Writing, de Lismore, na Irlanda (15a edição em 2018), ou o Festival Étonnants Voyageurs, sediado em Saint-Malo, França (29a edição em 2018).

Nesse último evento, aliás, o escritor francês Gilles Lapouge é presença constante, ano após ano, pois é um prolífico contador de histórias de viagem. Como ele mesmo diz em entrevista ao programa de TV da internet Un livre, un jour, de 19 de maio de 2009, Lapouge prefere as viagens narradas às vividas. É, portanto, na qualidade de contador de histórias de viagem que o escritor se coloca em seus mais de vinte romances e no Dictionnaire amoureux $d u$ Brésil, publicado na França em 2011 e traduzido no Brasil em 2014 por Maria Idalina Ferreira Lopes, com o título de Dicionário dos apaixonados pelo Brasil. O escritor, que também é jornalista, colabora com o jornal $O$ Estado de $S$. Paulo desde 1950, ano em que 
veio ao Brasil pela primeira vez. Aqui viveu até 1953 e desde então visita o país com frequência, tendo-o retratado em várias de suas obras, tais como Équinoxiales (1977), Au revoir l'Amazonie (2000), Nuits tranquilles à Belém (2015), dentre outros textos.

Seu amor pelo Brasil, declarado em inúmeras entrevistas disponíveis na internet (2009, 2011, 2015a, 2015b, 2017), credenciou Lapouge a escrever o volume dedicado ao país para a coleção Dictionnaire Amoureux, da editora francesa PLON. Sob a direção de JeanClaude Simoën, o primeiro Dictionnaire Amoureux foi lançado em novembro de 2000 e a coleção conta, atualmente, com 98 volumes. A estrutura, como o próprio título indica, é ao mesmo tempo bastante rígida, composta por verbetes ordenados alfabeticamente, como um dicionário deve ser, e livre, pois a escolha desses verbetes é dada pela subjetividade ou pela paixão do autor.

Lapouge, em seu Dicionário dos apaixonados pelo Brasil, escolhe não tratar de temas evidentemente ligados à cultura brasileira, como o futebol, o carnaval e o biquíni fio dental; em entrevista à rádio France Culture, em 2011, afirma que optou por não tratar deles por considerá-los lugares-comuns. Evitar tais assuntos demonstra uma certa preocupação com a originalidade de seu ponto de vista sobre o país; ou, pelo menos, a busca por um olhar próprio, pessoal, sobre o Brasil.

O Dicionário é composto por verbetes dedicados à fauna e à flora brasileiras, como o babaçu, o café, os "peixinhos", as "pombas de Sorocaba", a sucupira. Há também verbetes sobre personalidades, como Jorge Amado, Chica da Silva, Jean-Baptiste Debret, Lévi-Strauss, Hercule Florence, Paulmier de Gonneville e Pierre Verger, ou tipos brasileiros, como os seringueiros, os cangaceiros, os bandeirantes, os evangélicos, os poetas nordestinos. Há espaço, ainda, tanto para curiosidades linguísticas, como em "língua geral", em "língua particular", em "falsos cognatos" e no verbo "janelar", como para fatos folclóricos, como a lenda da "mulher da capona" e a literatura de cordel. Porém, salta aos olhos o grande número de verbetes dedicados aos espaços brasileiros, a começar por "Imensidões", passando por cidades, Estados e regiões - Amazonas, Salvador, Rio de Janeiro, Brasília, São Paulo, Recife, São Luís, Belém e as favelas. Nota-se, pelos nomes que elenquei, a predominância das regiões norte e nordeste em detrimento do sul e do sudeste, escolha justificada em entrevista concedida à rádio France Info, no quadro France Info Culture, em 2011, em que o autor declara conhecer pouco o sul do país.

Dentre esses espaços brasileiros, destaco o Rio de Janeiro, cujo verbete revela a imagem da cidade aos olhos do escritor-viajante-estrangeiro. Trata-se de uma rica amostra da composição mista do livro: à informação do viajante mescla-se a efabulação do escritor, tudo sob um olhar estrangeiro que, portanto, estranha tudo e descobre detalhes que passam despercebidos aos olhos dos locais. Para Jean-Marc Moura, teórico da Imagologia,

\footnotetext{
As imagens do estrangeiro fazem parte das representações mais antigas da humanidade; tão velhas, provavelmente, quanto a constituição das sociedades humanas. Marcando a fronteira da sociedade, o estrangeiro remete à verdade desta, ao que ela exclui e, portanto, ao que ela preserva como fundamentalmente seu. (MOURA, 1998, p. 35)
}

As lentes de Lapouge podem, portanto, ser reveladoras de uma realidade distinta tanto da vivenciada pelos moradores da cidade, quanto da imagem estereotipada de um olhar distante: o Rio de Janeiro é conhecido no exterior pelas praias, pela exuberância das mulheres de biquini, pelo samba nas favelas e pelo espetáculo do carnaval, em que desfilam mulatas sensualmente desnudas. Em entrevista do autor já mencionada neste artigo, fica claro que essa imagem se confunde com a do Brasil e que Lapouge a repudia, com base em sua larga 
vivência no país. Seu olhar, portanto, é o de um estrangeiro, porém de um estrangeiro bastante crítico, avisado, atento às idiossincrasias da cidade.

Seu verbete sobre o Rio se inicia por uma pequena parte histórica, que remonta ao descobrimento do Brasil e à tentativa da implantação da França Antártica, com Villegaignon. Segue-se uma parte em que são enumerados testemunhos de artistas e escritores estrangeiros que conheceram o Rio de Janeiro para, então, iniciar-se a segunda parte do verbete, em que Lapouge enuncia seu olhar sobre a cidade.

A função informativa do dicionário, é, portanto, desempenhada pela reconstituição da história da cidade sob o ponto de vista dos estrangeiros europeus, notadamente franceses. Ora, tal seleção não é fortuita: Lapouge retraça uma pequena genealogia de que ele mesmo, nos séculos XX e XXI, faz parte, enquanto francês que viveu no Brasil e pelo país viajou. Sua narrativa histórica, contudo, não é isenta: já no primeiro parágrafo o autor manifesta seu ponto de vista sobre a descoberta portuguesa, caracterizando-a como "uma baía magnífica" e como "este lugar excepcional", para inferir: "Sem dúvida, eles [os portugueses] pensam que ela é bonita" (LAPOUGE, 2011, p. 561).

Ao passar à tentativa de estabelecimento da França Antártica, Lapouge transforma o conflito territorial entre portugueses e franceses em uma disputa em razão da beleza do lugar: "[...] em 1565, os portugueses, irritados com o fato dos franceses de Villegaignon terem ocupado de 1555 a 1560 uma ilhota da baía de Guanabara com o Forte Coligny, começam a pensar que este lugar é muito bonito" (2011, p. 561-562). Concluindo a parte dedicada à descoberta do Rio de Janeiro, o autor, à maneira de um pintor viajante, salpica seu texto com personagens de pinturas de Debret, para descrever a ascensão da cidade a capital do império e da república. Para tanto, ele adota o ponto de vista do estrangeiro observador, que implica uma distância enunciativa, como segue: "A cidadezinha colonial se transforma. Ei-la aqui recheada de mordomos, barões, escravos, tabeliães, protocolos, oficiais de justiça, gargantas e pretensões" (2011, p. 562).

O elogio do Rio continua na introdução aos relatos dos viajantes que conheceram o local. Para Lapouge, se os gregos o tivessem visto, seria a oitava maravilha do mundo antigo (2011). As palavras de Auguste de Saint-Hilaire, em 1816, demonstram o deslumbramento diante da floresta próxima à cidade e da própria baía de Guanabara. Num salto temporal, Stefan Zweig, num trecho da Pequena viagem ao Brasil (1938), publicado na edição especial do Suplemento Literário do jornal carioca A Manhã, uma semana após sua morte, que ocorreu em fevereiro de 1942, é evocado para descrever a noite carioca como um misto de elementos poéticos e de imagens fantásticas, criando uma atmosfera extraordinária, situada entre o sonho e a realidade, bem ao gosto do escritor Lapouge que, lembro, preferia uma viagem narrada a uma viagem vivenciada:

[...] Subitamente um raio caiu ao longe, no fundo da baía gigantesca e, de um só golpe, todos os postes de luz ao longo do mar foram iluminados. Uma serpente luminosa fina, porém interminável, desposa, enrolando-se em si mesma, essa linha sinuosa e traça sobre todo o contorno geográfico da costa uma longa faixa de fogo e, em sua extremidade, essa serpente está ornada, não com a coroa de rubis do conto, mas com uma coroa feita com todas as luzes do centro. (ZWEIG, 1942, p.108 apud LAPOUGE, 2011, p. 563)

O intertexto com "Encanto da noite", de Zweig, coloca sob a pluma do escritor austríaco o encantamento da visão do anoitecer na Baía de Guanabara. A "Fada Eletricidade", para citar o título do grandioso e não menos encantado painel de Raoul Dufy ${ }^{\text {ii }}$ de 1937, parece seduzir Zweig, conduzindo-o para um mundo fantástico, em que desfilam, sinuosas, "serpentes luminosas". Tal foi a sensação quando da chegada da iluminação elétrica às ruas 
de Paris, em 1878, por ocasião da Exposição Universal, momento em que, exibindo o que era visto como a fonte de energia do futuro, algumas praças e avenidas da cidade foram iluminadas com eletricidade. Dois anos mais tarde, iniciou-se a progressiva substituição das lâmpadas a gás pelas elétricas.

No Rio de Janeiro, o mesmo fenômeno se repetiu em 15 de novembro de 1905, quando foi inaugurada a iluminação elétrica na Avenida Rio Branco, então Avenida Central. Desde então, pouco a pouco, a fraca luz das lâmpadas a gás cedeu lugar para a frenética luz elétrica, descrita no Editorial da revista Fon Fon de 7 de agosto de 1909, nos seguintes termos: "A Avenida regurgitava e a iluminação era profusa, dir-se-ia o laboratório gigantesco de um eletricista maníaco, tão forte, tão demasiada, era a irradiação das lâmpadas! Carruagens, pessoas, automóveis, tudo tumultuava uma ebriedade de viver!" $(1909$, p. 8).

A atmosfera mágica, que transforma a rua num "laboratório gigantesco de um eletricista maníaco" é a mesma em que evolui, em movimentos circulares, a "serpente luminosa" de Zweig. Inebriado pela forte luz elétrica, como se evocasse uma lembrança de infância - o escritor nasceu em 1881 tendo, talvez, presenciado a transição da iluminação a gás para a elétrica -, ele transpõe o clima do final do século XIX na Europa e do início do século XX no Brasil para a paisagem carioca de 1938, dotando a Baía de Guanabara de uma aura enfeitiçante, que só faz realçar os elogios ao Rio.

Nessa descrição feérica do espaço, a fabulação torna-se ainda mais maravilhosa com um segundo intertexto, desta feita estabelecido, não por Lapouge, mas por Zweig com o conto dos irmãos Grimm, "O pescador e sua mulher”. Publicada originalmente em 1812 no primeiro volume da coletânea Contos de Grimm, a narrativa conta a história de um pescador pobre que, um dia, pesca um peixe mágico. Libertando-o, adquire o direito de lhe pedir qualquer coisa que, pela ambição de sua mulher, transforma-se progressivamente em mais poder e posses: de uma casinha vai a um castelo, do desejo de se tornar rainha, passa a ser imperatriz, até chegar a papisa. Quando ela expressa o desejo de se tornar Deus, o peixe faz o casal retornar a sua condição de pobreza inicial. Para enfatizar a moral da história, punindo a ambição desmedida da mulher, sua riqueza progressiva é descrita em detalhes, o que inclui uma coroa de rubis, como a mencionada por Zweig. Dentro desse contexto ficcional, a serpente de luz carioca acrescenta ao fausto da coroa de rubis da mulher do pescador as luzes elétricas dos postes da Baía de Guanabara, contribuindo para a criação de uma imagem maravilhosa do Rio de Janeiro.

Dando continuidade aos relatos dos viajantes que por lá passaram, Lapouge cita Alexander von Humboldt, que compara o Rio a Nápoles e a Salzburg, consideradas por ele as cidades mais belas do universo. Já o francês Georges Clemenceau, ao chegar de navio no início do século XX, descreve a cidade como "alegrada por praias risonhas, florida por ilhas misteriosas", que mistura "à sombra clara das plantas frondosas todo o fascínio do céu e do mar nas volúpias do sol", concluindo com uma imagem etérea: "Nós estamos navegando em uma nuvem" (2011, p. 563). Para resumir, o autor faz uma lista de viajantes franceses que estiveram no Brasil no século XX, afirmando: "não há um único viajante da Europa que não se extasie diante da grande ópera que o Rio de Janeiro apresenta, sem falta, há dois séculos" (2011, p. 564). Só há uma exceção: Claude Lévi-Strauss.

As opiniões do célebre etnólogo estabelecem um contraponto ao discurso entusiasta predominante, vendo na distribuição dos acidentes geográficos na Baía de Guanabara uma boca desdentada (2011). Face às belezas cantadas em verso e prosa por tantos escritores, Lévi-Strauss, nos termos de Lapouge, "mantém-se frio" (2011, p. 564). O que não surpreende o escritor. No início dos anos 50, antes da publicação de Tristes Trópicos (1955), Lapouge, pela primeira vez no Rio, e para surpresa dos leitores do Dicionário, também emitia uma visão negativa sobre a cidade, paradoxalmente provocada pelo excesso de beleza natural da 
Baía de Guanabara, pelo excesso de confiança dos cariocas na praia, exibindo seus corpos, pelo excesso de arrojo urbanístico dividindo a cidade entre túneis e morros, enfim, pelos excessos do Rio.

Tamanho esplendor não poderia durar para sempre. E não durou. Lapouge passa a narrar a decadência da cidade, causada pela fundação de Brasília, que tirou do Rio o nobre título de capital do país. A crise foi agravada pela situação geral do Brasil, sob o jugo militar a partir de 1964. O panorama geral dos anos 80 e 90 evidencia São Paulo como capital financeira, Brasília como capital política e o Rio... Como capital da poesia, da malandragem, do riso, enfim, de um modo de vida alegre e triste, dividido entre a miséria das favelas, nos morros, e a bossa nova, no asfalto. O Rio se transformou - "(de uma cidade a história/ Depressa muda mais que um coração infiel);", na tradução de Ivan Junqueira (BAUDELAIRE, 2006, p. 301) -, como escrevia a voz lírica de Baudelaire a respeito de Paris no poema "O Cisne", quando das profundas transformações urbanísticas impostas pelo Barão de Haussmann entre 1852 e 1870.

A cidade, então, é personificada sob a pluma de Lapouge: "Então, como é preciso fazer alguma coisa quando se é uma cidade, o Rio se reciclou. Ele passou a se dedicar a seu declínio. Fez disso uma obra de arte" (LAPOUGE, 2011, p. 569). O Rio, portanto, precisa tomar um rumo, como se fosse uma pessoa, e decide aceitar seu declínio, tirando dele sua beleza. Ora, não é esse um dos grandes gestos das Flores do Mal (1857), do mesmo Baudelaire? Num dos poemas mais célebres dessa obra, "Uma Carniça", descrevendo a carniça do título, o poeta escreve os seguintes versos: "E o céu olhava do alto a esplêndida carcaça/ Como uma flor a se entreabrir" (BAUDELAIRE, 2006, p. 175). Com um simples comparativo - que sempre é mais do que isso em seus poemas -, "como", Baudelaire metamorfoseia os restos de um animal em decomposição num símbolo de beleza, a flor, materializando poeticamente a "flor do mal" de seu título. Para Lapouge, a flor carioca tem a mesma natureza baudelairiana.

Adiante, o escritor desenvolve um pouco mais a personificação da cidade: "Esta [a decadência] do Rio é lenta, mascarada, glutona e voluptuosa. Esta cidade é um grande poeta; de seu declínio fez um esplendor" (2001, p. 570). No poema-prefácio de As Flores do Mal, "Ao Leitor", o poeta faz o elogio da decadência moral de seu tempo, enfatizando o movimento contínuo e prazeroso com que avançamos para o mal: "E alegres retornamos à lodosa estrada" ou, em outra estrofe: "Dia após dia, para o inferno caminhamos, / Sem medo algum, dentro da treva que nauseia" (BAUDELAIRE, 2006, p. 111 e 113). A identificação da cidade com um "grande poeta" nos confirma: Lapouge está seguindo os passos de Baudelaire para escrever sobre o Rio de Janeiro. O caráter ambivalente da beleza carioca tem parentesco com a descrição da Beleza baudelairiana do "Hino à Beleza": "Vens tu do céu profundo ou sais do precipício, / Beleza?" (2006, p. 159) Ou, nos termos de Lapouge, emprestados de uma entrevista de Walter Salles e populares na linguagem corrente, a beleza do Rio vem dos morros ou do asfalto, este, paradoxalmente, sendo o equivalente ao "céu profundo" e os morros correspondendo ao "precipício". As duas últimas estrofes do poema desenvolvem essa ideia:

Que venhas lá do céu ou do inferno, que importa,

Beleza! ó monstro ingênuo, gigantesco e horrendo!

Se teu olhar, teu riso, teus pés me abrem a porta

De um infinito que amo e que jamais desvendo?

De Satã ou de Deus, que importa? Anjo ou Sereia,

Que importa, se és quem fazes - fada de olhos suaves,

Ô rainha de luz, perfume e ritmo cheia! -

Mais humano o universo e as horas menos graves?" (BAUDELAIRE, 2006, p. 161)

IPOTESI, JUIZ DE FORA, v.22, n.1, p. 30-38, jan./jun. 2018 
A Beleza monstruosa, oxímoro estético criado por Baudelaire, é empregado por Lapouge para caracterizar o Rio de Janeiro, a "serpente luminosa", nos termos de Zweig, "fada de olhos suaves" ou fada elétrica, voltando ao painel de Dufy. Seja como for, "Anjo ou Sereia", no poema, a Beleza torna a vida mais suportável, menos horrenda e mais leve.

Com todas as contradições reunidas, o Rio de Lapouge é o Rio do carnaval, descrito tanto em detalhes de bastidores, que citam o financiamento oriundo do jogo do bicho e o árduo trabalho de um ano inteiro para o desfile de uma noite, quanto em seu aspecto grandioso. O carnaval do Rio é a maior festa popular do mundo, onde "Por algumas horas, a baía de Guanabara é o luxo do mundo" (2011, p. 571). E poderíamos acrescentar o refrão do poema em versos "O Convite à viagem", de Baudelaire: "Lá, tudo é paz e rigor, / Luxo, beleza e langor." (2006, p. 225), uma vez que Lapouge cita um outro trecho do mesmo poema, precedido por: "No porto, navios desembarcam seus carregamentos de turistas vindos dos confins da Terra" (2011, p. 225).

\author{
- Os sanguíneos poentes \\ Banham as vertentes, \\ Os canais, toda a cidade, \\ E em seu ouro os tece;" (BAUDELAIRE, 2006, p. 227).
}

A citação desses versos reforça o intertexto com a estética baudelairiana, por meio da literatura, concedendo à cidade uma aura poética, voluptuosa e irreal, como o destino do "Convite à viagem". Num certo sentido, Lapouge convida seus leitores a fazer uma viagem ao Rio de Janeiro, tal como o poeta convida sua amada a uma viagem "No país que é a tua imagem!" (2006, p. 225) O espelhamento entre pessoas e paisagens, como no poema e como no verbete, onde Lapouge personifica a cidade, acaba por estabelecer não um diálogo, mas um "pluriálogo", se o neologismo me é permitido, capaz de dar conta da pluralidade de vozes que integra a conversa. Pois o autor, em sua escrita, trilha caminhos que o conduzem para longe das largas avenidas dos lugares comuns. Ele busca conhecer o detalhe ínfimo do cotidiano, para a partir daí imaginar, criar, efabular, escrever. Baudelaire já expressava a mesma curiosidade no poema em prosa "As Janelas", em que a voz lírica explicita seu interesse pelas janelas fechadas, maior do que pelas janelas abertas, pois aquelas permitem que se imagine o que se passa no interior da morada: "Quem olha de fora por uma janela aberta nunca vê tanta coisa quanto quem olha por uma janela fechada." (BAUDELAIRE, 1995, p. 115) O poeta exemplifica sua teoria com a imagem de uma senhora pobremente vestida, debruçada sobre alguma coisa que ele vê através da janela, o que lhe permite criar uma história: "[...] Com seu rosto, com sua roupa, com seu gesto, com quase nada, refiz a história dessa mulher, ou melhor, a lenda, que às vezes, chorando, conto para mim mesmo." (1995, p. 115) A conclusão, que coloca frente a frente realidade e ficção, não poderia ser diferente: 'Talvez me digam: 'Tem certeza de que essa lenda é a verdadeira?' Pouco importa o que seja a realidade fora de mim, se ela me ajudar a viver, a sentir o que sou e quem eu sou." (1995, p. 116) Ou seja, a criação ficcional não é mera recreação, mas condição de existência do escritor.

Vai na mesma direção apontada por Baudelaire o que escreve Lapouge em outro verbete do Dicionário, dedicado aos "Encontros":

Em suma, gostaria de me introduzir por meio de um arrombamento silencioso em um país, em um destino, em uma vida onde tudo estaria em seu lugar e no qual só estivesse faltando, até aquele momento, eu. Preencher o vazio que ocupava meu lugar. Instalar-me sobre a minha sombra $(2011$, p. 556). 
O escritor, assim como o poeta, tem o desejo de criar uma narrativa a partir de alguns parcos dados cotidianos de desconhecidos que ele vê pela janela, no caso de Baudelaire, ou observa durante uma viagem, para Lapouge. Porém, se o poeta procura ser autor, narrador e leitor da história criada, o escritor contemporâneo deseja se tornar personagem de uma história pré-existente.

Preferências sobre as instâncias narrativas à parte, os dois escritores, assim como o homem das multidões de Edgar Allan Poe, não por acaso traduzido por Baudelaire, têm necessidade de se fundir com os objetos de suas observações. Somente por meio da literatura isso é possível, o que Lapouge deixa claro neste trecho do verbete "Encontros":

Eis o que é a viagem: fundir-se à paisagem e se infiltrar, como se fosse invisível, em uma das existências que fazem parte dessa paisagem. Eu acabaria por visitar a mim mesmo, por perguntar a mim mesmo quem eu sou. Seria inebriante. Mudar-se para o lugar que estava à minha espera como me esperam milhões de lugares que nunca conhecerei pois, enfim, não se pode viajar sem parar. (2011, p. 557)

A proximidade com Baudelaire de "As Janelas" é evidente: como o poeta, Lapouge também tem necessidade de se fundir com o que vê, a paisagem, para sentir que "ele existe e quem ele é", para citar, adaptando, o poema em prosa. Por meio da literatura - não somente graças à compreensão tradicional da leitura como maneira de viver outras vidas e de conhecer lugares diferentes - os escritores se incorporam à ficção, vivenciando-a, sem, todavia, deixar de ser escritores. Somente a dupla consciência, de autor e de instância narrativa ou poética, permite a Baudelaire e a Lapouge a descoberta de outras vidas e territórios, bem como a própria descoberta de si mesmos. O que vai ao encontro da particularidade do texto literário nascido da experiência com o estrangeiro, segundo Jean-Marc Moura: "As novas imagens dos alhures, por vezes reatando com representações bastante antigas, nascem da desordenação da herança intelectual e narrativa devido ao reencontro criativo entre um escritor e um espaço diferente, mas estranhamente acessível a experiências decisivas.” (1998, p. 07).

Nesse sentido, o Dicionário de Lapouge se constitui como uma série de relatos de viagem que são encontros do autor com paisagens, pessoas, animais, hábitos, histórias, informações. Como em "O Convite à viagem" e em "As Janelas" de Baudelaire, como o personagem de Poe, Lapouge se confunde com seu objeto e se torna personagem de seus textos. O Rio de Janeiro carnavalesco do escritor é um lugar de encontros, do autor com a cidade, mas também do autor com sua memória, como ele escreve: "O carnaval é também um grande entreposto de lembranças e de tempos recuperados" (2011, p. 573). Como os encontros de carnaval que duram uma vida inteira, esta é a história de amor de Lapouge com o Rio.

\title{
A fairy and decadent Rio de Janeiro
}

\begin{abstract}
This article aims to analyse French writer Gilles Lapouge's regard to Rio de Janeiro from the entry about the city in his Dictionnaire Amoureux du Brésil, published in 2011. The dialogues with other travelwriters who have visited Rio, as Stefan Zweig, or as a writer who was always looking for the evasion from the reality through the travel subject, Baudelaire, lead to the construction of the image of the city by Lapouge, which oscillates between a fairy and decadent Rio de Janeiro.
\end{abstract}

Keywords: Gilles Lapouge; Rio de Janeiro; travel-writers. 


\footnotetext{
* Laura Taddei Brandini é mestre e doutora em Literatura Francesa e Literatura e Estética pela USP e pela Universidade de Genebra, com pós-doutorado em Literatura Comparada obtido na Universidade de Paris IV Sorbonne, em 2014-2015. Desde 2009 é professora de Literatura Francesa na Universidade Estadual de Londrina.

i Todas as traduções são de responsabilidade da autora, salvo menção contrária.

ii Painel de 10 x 60 m realizado para a Exposição Universal de Paris de 1937, encontra-se exposto no Museu de Arte Moderna da Cidade de Paris.
}

\section{REFERÊNCIAS:}

BAUDELAIRE, Charles. As Flores do mal.Edição bilíngue. Tradução, introdução e notas de Ivan Junqueira. Rio de Janeiro: Nova Fronteira, 2006.

O Spleen de Paris. Pequenos poemas em prosa. Tradução de Leda Tenório da Motta. Rio de Janeiro: Imago, 1995.

DAMROSCH, David. What is World Literature ? Nova Jersey (EUA) : Princeton University Press, 2003.

FON FON. Semanário Ilustrado. "Pelos Sete Dias". Rio de Janeiro, ano III, número 32, 7 de agosto de 1909, $\quad$ p. 8.0 Disponível http://objdigital.bn.br/acervo_digital/div_periodicos/fonfon/fonfon_anos.htm. Acesso em 06/07/2018.

GRIMM, Jacob e Wilhelm. "Le pêcheur et sa femme". Tradução de Frédéric Baudry. Paris: Hachette, 1864, pp. 59-73. Disponível em:

https://fr.wikisource.org/wiki/Contes_choisis_des_fr\%C3\%A8res_Grimm/Le_P\%C3\%AAcheur_et_sa _femme. Acesso em 06/07/2018.

LAPOUGE, Gilles. Dictionnaire Amoureux du Brésil. Paris: PLON, 2011.

Dicionário dos Apaixonados pelo Brasil. Tradução de Maria Idalina Ferreira Lopes. Barueri (SP): Amarilys, 2014.

Gilles Lapouge: La Légende de la géographie. Entrevista concedida a Olivier Barrot para o programa Un livre, un jour. Paris, 19 de maio de 2009. Disponível em: http://www.ina.fr/video/3913219001. Acesso em 06/07/2018.

. "Continuo apaixonado pelo Brasil". Entrevista concedida a Roberto Gazzi para a TV Estadão. São Paulo, 13 de abril de 2015a. Disponível em: https://www.youtube.com/watch?v=_wg321PMbbA. Acesso em 06/07/2018.

Entretien de Gilles Lapouge sur le Dictionnaire Amoureux du Brésil. Entrevista concedida a France Info Culture. Paris, 2011. Disponível em: https://www.dailymotion.com/video/xj7uqv. Acesso em $06 / 07 / 2018$.

Roda Viva Internacional: Gilles Lapouge. Entrevista concedida a vários jornalistas para a TV Cultura. São Paulo, 02 de julho de 2015b. Disponível em: https://www.youtube.com/watch?v=5qD19ZEAu_Q. Acesso em 06/07/2018.

MOURA, Jean-Marc. Europe littéraire et l'ailleurs. Paris: PUF, 1998. 
ZWEIG, Stefan. "Encanto da noite". In Autores e Livros, Suplemento Literário de A Manhã. Rio de Janeiro, volume 11, número 7, ano II, $1^{\text {o }}$ de março de 1942, p. 108. 